\title{
THE EFFECTIVENESS OF 'PRACTICE WHILE WATCHING' TECHNIQUE FOR THE FIRST AID TRAINING OF THE CHEMICAL INDUSTRY EMPLOYEES
}

\author{
Radoslaw Zalewski ${ }^{1}$, Piotr Przymuszala ${ }^{2}$, Tomasz Klosiewicz ${ }^{1}$, Marek Dabrowski² ${ }^{(1 D}$, \\ Ryszard Marciniak² ${ }^{\text {(D) }}$ Magdalena Cerbin-Koczorowska² \\ ${ }^{1}$ Department of Medical Rescue, Chair of Emergency Medicine, Poznan University of Medical Sciences, Poznan, Poland \\ ${ }^{2}$ Chair and Department of Medical Education, Poznan University of Medical Sciences, Poznan, Poland
}

\begin{abstract}
INTRODUCTION: Industrial accidents constitute about $20 \%$ of all causes of accidents. They are often sudden, unexpected and may lead to tragic consequences, which however can be partially reduced if first aid and emergency treatment are given as soon as possible. The most important part of a chain of survival is the bystanders' response. In practice, it is highly dependent on the ability of co-workers to perform basic first-aid tasks. The aim of this paper was to present the effectiveness of 'practice while watching' training method for the first aid training of the chemical industry employees. The authors focused on the most important elements of the training, which have an impact on the acquisition of knowledge and skills of first aid.
\end{abstract}

MATERIAL AND METHODS: The training involved 69 employees of the chemical industry. The test sheets were used for the assessment, where each of the action steps was assigned points 0 for incorrect and 1 for a properly performed activity.

RESULTS: Each step was completed by at least $76 \%$ of workers. When providing both adult and infant CPR, the main difficulty was calling for help. Younger employees obtained better results than older colleagues.

CONCLUSIONS: The study demonstrated the high effectiveness of the 'practice while watching' method. In addition, workers' age turned out to be a significant variable which affected their performance.

KEY WORDS: audio-visual aids; cardiopulmonary resuscitation; employee training; first aid training; 'practice while watching' technique

Disaster Emerg Med J 2019; 4(3): 83-91

\section{INTRODUCTION}

Chemical industry constitutes nowadays a major part of the modern world economy producing more than $\mathbf{4 0 0}$ million tons of different chemicals per year [1] and creating numerous job places worldwide. In 2015 world chemicals turnover was valued at $€$ 3,534 billion and was majorly dominated by China, followed by the United States of America, Germany,
Japan and South Korea [2]. However, the mishandling of chemical substances may impose significant consequences for the environment as well as for humans resulting in injury, disabilities or even death of one or more individuals. It is therefore important to promote safety and prevention among employees of the chemical sector and increase awareness of the potential risks and the methods of reducing them.

ADDRESS FOR CORRESPONDENCE:

Marek Dabrowski, Chair and Department of Medical Education, Poznan University of Medical Sciences, Poznan, Poland University of Medical Sciences, 7 Rokietnicka Str., 60-806 Poznan, Poland e-mail: maro.dabrowski@gmail.com 
Industrial accidents constitute about $20 \%$ of all causes of accidents [3]. Their frequent occurrence was shown to be in $80-90 \%$ of cases caused by human errors whereas environmental conditions are responsible for $10-20 \%$ of them [3]. Significance of human errors is also emphasized by the observation that the industrial accidents happen more often within first half of the morning shift and at fifth or sixth hour in the night shift as a result of growing fatigue [4].

Industrial accidents are often sudden, unexpected and their consequences may be tragic, including severe body trauma and disablement or in the worst-case scenario even fatal, causing distress and economic problems to their victims and their families and generating costs for national economies estimated as $3 \%$ to $5 \%$ of the gross national product [5]. retrospective analysis, However, often shows that they could have been prevented by adequate training of workers and introducing safer working conditions $[6,7]$. Nevertheless, if the industrial accident happens, its tragic consequences can be at least partially reduced if first aid (immediate help given to the victim, before treatment may be provided by qualified health personnel) and emergency treatment are given immediately [5]. They may improve the chances for survival, diminish the costs of treatment and rehabilitation and reduce the time of hospitalization [8]. Medicine has advanced significantly over past few decades and is now able to save people even in very serious conditions, given they receive proper help prior to the arrival of specialized medical care, as often the first few minutes after an accident may be crucial for survival. In practice, whether the victim receives first aid is highly dependent on the ability of witnesses (in case of industrial accidents often co-workers) to perform basic first-aid tasks [9]. Hatzakis et al. showed that the majority of industry workers do not possess sufficient knowledge regarding first aid [5]. The study presented a large number of workers unable to give correct answers even to simple questions such as pulse rate or ratio of ventilations to chest compressions in CPR. Simultaneously a high percentage of employees declared willingness to give help in case of an accident.

Effectiveness of first aid training has been a subject of many studies and it was found that experimental groups who had undergone it, generally received a higher number of correct answers than the control groups [3]. In a study carried out by Lingard, it was also observed that introducing the first aid training in a workplace had a positive preventive effect on the occupational safety of employees and improvement of their risk control behaviour making them more aware of potential hazards and enhancing their motivation to avoid them. It seems therefore even more beneficial to introduce first aid training to all employees rather than only to selected members of staff [10].

Adequate training should basically consist of two parts: theoretical and practical. theory behind it, However, should only give general notion and understanding why specific action is implemented. The greater emphasis ought to be put on the practical aspect of training which should correspond with the amount of time dedicated to it. Simulation-based training methods have been proven effective in healthcare workers education in case of both theory and practice $[11,12]$. Still, training should correspond with circumstances potential rescuers work in [13]. Taking all of the above into consideration, the aim of this article is to present 'practice while watching' method of teaching first aid developed by American Heart Association to employees of the chemical industry and to verify its effectiveness with attention especially to the most vital elements of first aid training that influence assimilation of knowledge and gaining practical skills.

\section{Sample}

\section{MATERIAL AND METHODS}

The examined group consisted of 69 employees of the heavy chemical industry (49 males and 20 females) aged 26 to 55 who were trained with 'practice while watching' method. The median age was equal to 35 so for further analysis the examinees were divided into two age groups. The detailed characterization of the examined group is presented in Table 1.

\section{Educational intervention}

A standardized Heartsaver CPR and AED educational intervention were used in the study. Preparing for teaching begins approximately 30 days before the day of the course. Examinees were divided into 6 training groups (5 groups of 12 people and 1 of 9) and every group completed six hours of training course. American Heart Association does not impose the number of participants taking part in the training since the optimal student-instructor ratio has not yet been determined. In the project, 3 AHA instructors were present every day of the training and 


\begin{tabular}{|c|c|}
\hline \multicolumn{2}{|c|}{ Gender } \\
\hline Male & $49 ; 71.02$ \\
\hline Female & $20 ; 28.98$ \\
\hline Total & $69 ; 100.00$ \\
\hline \multicolumn{2}{|c|}{ Age } \\
\hline$\leq 35$ & $37 ; 53.62$ \\
\hline$>35$ & $32 ; 46.38$ \\
\hline \multicolumn{2}{|c|}{ Working position } \\
\hline Assembly line operator & $44 ; 63.77$ \\
\hline Transport operator & $9 ; 13.04$ \\
\hline Administrative worker & $9 ; 13.04$ \\
\hline Production area leader & $4 ; 5.80$ \\
\hline Laboratory worker & $3 ; 4.35$ \\
\hline \multicolumn{2}{|c|}{ Formal Education Level } \\
\hline Primary or vocational & $15 ; 21.74$ \\
\hline Secondary & $36 ; 52.17$ \\
\hline Higher & $18 ; 26.09$ \\
\hline
\end{tabular}

every one of them was evaluating simultaneously 3 training stations. In our study the ratio of participants to training stations was equal to 2:1. AHA emphasizes to ensure the highest possible number of phantoms. In our study we used 6 adult phantoms (Little Anne by Laerdal, Norway), 6 infant phantoms (Baby Anne by Laerdal, Norway) and 4 training AED defibrillators (AED Trainer XFT-120 C+). Additional equipment involved elements necessary to display instructional video - multimedia projector, loudspeakers and DVD player. The classroom was set up to ensure that participants can comfortably observe the instructional video while kneeling next to the phantom. The Heartsaver course is divided into 2 basic modules which are presented in Table 2 .

\section{Evaluation settings and the research tool}

After the completion of every part, the participants underwent practical skills evaluations: adult CPR with AED and infant CPR. The research tool used in this study was evaluation forms consisting of 12and 11-points checklists for the assessment of respectively adult and infant CPR (Fig. 1 and 2). Due to the fact that evaluation of CPR skills in adults differs from the assessment criteria of practical training on infants, the numbers had to be rescaled to a neutral 0-100-point scale which allows comparison of performance to reflect a similarity. Each evaluation was conducted simultaneously by 3 instructors and the

\begin{tabular}{|c|c|}
\hline Module 1 & Module 2 \\
\hline \multicolumn{2}{|c|}{ Training with 'practice while watching' method } \\
\hline $\begin{array}{l}\text { - Proper and safe removal } \\
\text { of disposable gloves } \\
\text { contaminated with body } \\
\text { fluids of the victim } \\
\text { - Level of consciousness } \\
\text { and breathing assessment }\end{array}$ & $\begin{array}{l}\text { - Delivering chest } \\
\text { compressions to adults/ } \\
\text { /infants } \\
\text { - Delivering mouth-to- } \\
\text { mouth ventilation to } \\
\text { adults/infants } \\
\text { - Delivering rescue breaths } \\
\text { with a mask to adults/ } \\
\text { /infants } \\
\text { - Delivering CPR to adults/ } \\
\text { /infants }\end{array}$ \\
\hline \multicolumn{2}{|c|}{$\begin{array}{l}\text { Training without instructional videos, under the supervision } \\
\text { of the instructor }\end{array}$} \\
\hline $\begin{array}{l}\text { - Administration of } \\
\text { adrenaline prefilled } \\
\text { syringes } \\
\text { - Stoppage of bleeding } \\
\text { - Immobilisation of the } \\
\text { injured extremity }\end{array}$ & $\begin{array}{l}\text { - Using AED defibrillator } \\
\text { - Delivering CPR with AED } \\
\text { to adults/infants } \\
\text { - Full infant CPR algorithm }\end{array}$ \\
\hline
\end{tabular}

results were written down on evaluation forms. Having successfully finished and passed the training course, every participant is rewarded with a certificate issued by an authorized course organizer. It has been proven that the level of practical skills gained during a CPR course decreases sharply within a few months or even days after the first training [14]. However, no data are available on how often the course should be repeated and as a sort of compromise AHA has decided to grant certificates only for 2 years. After this period in order to renew it one has to take part in a recertification course.

\section{Statistical analysis}

Normal distribution of evaluation of skills in adult CPR and infant CPR, among participants, Shapiro-Wilk test was performed. To compare skills in adult CPR and skills in the field of infant CPR the non-parametric Wilcoxon test was used. To check the significance of differences in the level of skills in adult CPR vs. infant CPR, non-parametric tests were used: Kruskal-Wallis test (for comparison of three groups) and the Mann-Whitney test (for comparison of two groups). Correlations between quantitative variables were assessed using a non-parametric significance test: Spearman rank correlation coefficient. Statistically significant $p$-value $<0.05$ was utilized. Statistical calculations were performed using the Statistica 10 (Statsoft) software. 


\section{Heartsaver $^{\circledR}$ CPR AED Skills Sheet}

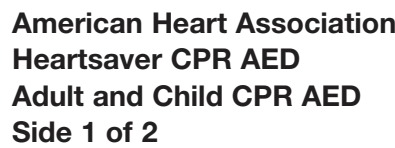

\begin{tabular}{|c|c|c|c|}
\hline Step & Gritical Performance Steps & $\begin{array}{l}\text { Adult CPR AED } \\
\checkmark \text { if done correctly }\end{array}$ & $\begin{array}{l}\text { Child GPR AED } \\
\checkmark \text { if done correctly }\end{array}$ \\
\hline 1 & Verbalizes that the scene is safe & & \\
\hline 2 & Checks for response-tap and shout & & \\
\hline 3 & Yells for help & & \\
\hline 4 & $\begin{array}{l}\text { Tells someone to phone the emergency response } \\
\text { number (or 911) and get an AED (for adult only) }\end{array}$ & & \\
\hline 5 & $\begin{array}{l}\text { Checks for no breathing or only gasping } \\
\text { Minimum } 5 \text { seconds; maximum } 10 \text { seconds }\end{array}$ & & \\
\hline 6 & $\begin{array}{l}\text { Locates hand placement for compressions } \\
\text { Moves clothes out of the way of the chest } \\
\text { Lower half of the breastbone; } 1 \text { or } 2 \text { hands for child }\end{array}$ & & \\
\hline 7 & $\begin{array}{l}\text { Delivers first set of compressions } \\
\text { Gives } 30 \text { compressions in } 18 \text { seconds or less }\end{array}$ & & \\
\hline 8 & $\begin{array}{l}\text { ADULT: Gives } 2 \text { breaths with a mask } \\
\text { CHILD: Gives } 2 \text { breaths without a mask } \\
\text { At least } 1 \text { breath results in visible chest rise } \\
\text { Breaths given and compressions started within } \\
10 \text { seconds }\end{array}$ & & \\
\hline 9 & $\begin{array}{l}\text { Delivers second set of compressions } \\
\text { Gives at least } 23 \text { of } 30 \text { compressions in the correct chest } \\
\text { location }\end{array}$ & & \\
\hline 10 & $\begin{array}{l}\text { ADULT: Gives } 2 \text { breaths with a mask } \\
\text { CHILD: Gives } 2 \text { breaths without a mask } \\
\text { At least } 1 \text { breath results in visible chest rise } \\
\text { Breaths given and compressions started within } \\
10 \text { seconds }\end{array}$ & & \\
\hline 11 & $\begin{array}{l}\text { Instructor says, "You have just completed } 5 \text { sets of } \\
\text { compressions and breaths." } \\
\text { Leaves to phone } 911 \text { and get an AED (for child only) }\end{array}$ & & \\
\hline 12 & Turns on the AED immediately after it arrives & & \\
\hline \multicolumn{4}{|c|}{$\begin{array}{l}\text { The next step is done only with a manikin with a feedback device designed to indicate when compressions are } \\
2 \text { inches deep (child) or more (adult) and/or indicate that chest recoil is complete. If no feedback device, } \\
\text { STOP THE TEST. }\end{array}$} \\
\hline 13 & $\begin{array}{l}\text { Delivers third set of compressions of adequate depth } \\
\text { Acceptable if at least } 23 \text { of } 30 \text { compressions indicate a } \\
\text { depth of at least } 2 \text { inches (adult) or about } 2 \text { inches (child) }\end{array}$ & & \\
\hline $2011 \mathrm{An}$ & Heart Association & STOP THE TEST & STOP THE TEST \\
\hline
\end{tabular}

\section{Record test results on bottom of side 2}

FIGURE 1. Evaluation form — Adult CPR 


\section{Heartsaver ${ }^{\circledR}$ CPR AED Skills Sheet}

\begin{tabular}{|l|}
\hline American Heart Association \\
Heartsaver CPR AED \\
Infant CPR \\
Side 2 of 2 \\
\hline
\end{tabular}

Student Name:

Test Date:

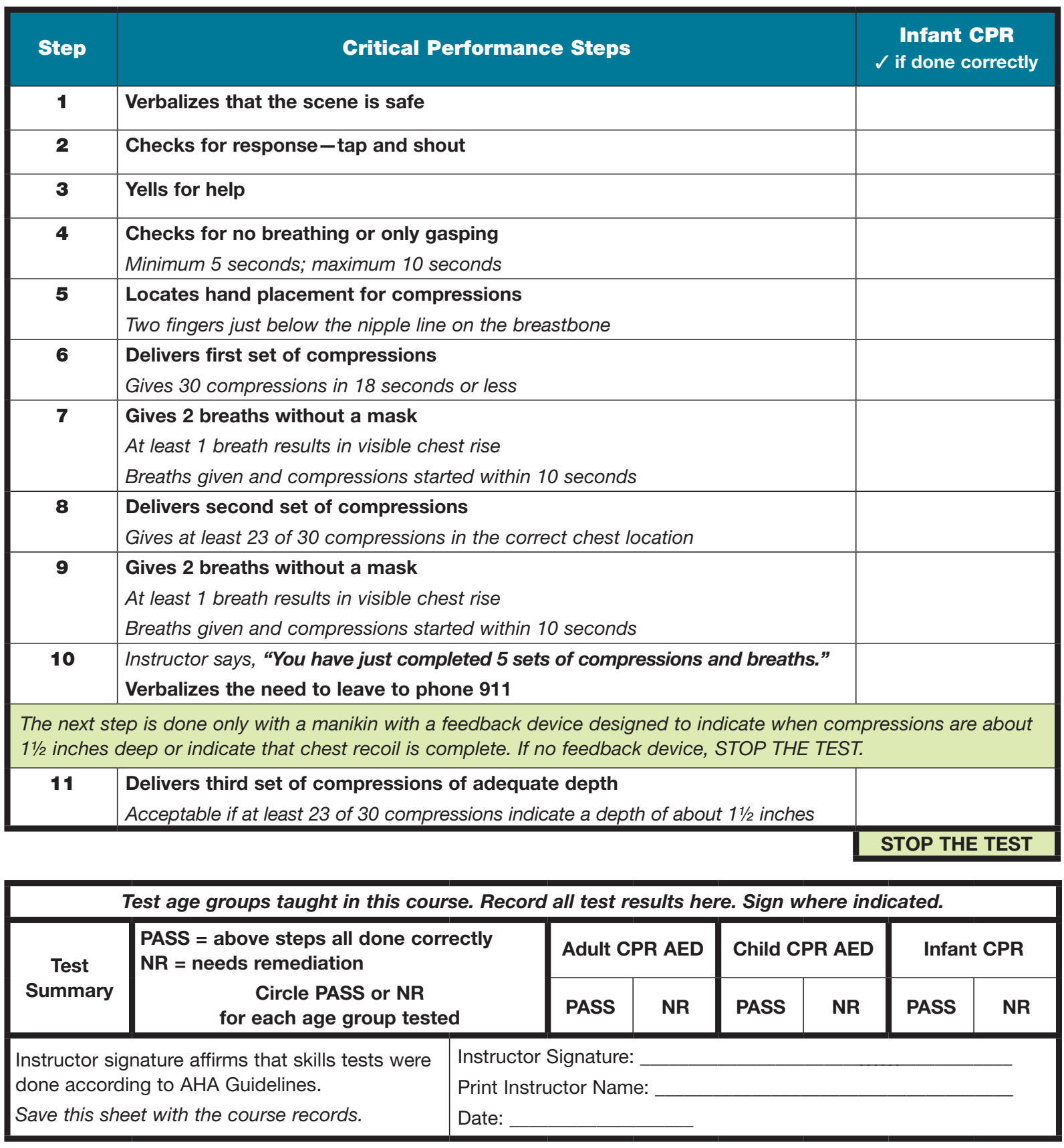

(C) 2011 American Heart Association

FIGURE 2. Evaluation form - Infant CPR 


\section{RESULTS}

Each step of both infant and adult CPR was completed by at least $76 \%$ of workers. The most striking result to emerge from the data is that the 'Yelling for help' stage of adult and infant CPR was incorrectly finished by a staggering $23.19 \%$ and $20.29 \%$ of workers, respectively.

When providing the adult CPR (Tab. 3), another $7.25 \%$ of learners failed at asking someone to phone the emergency response number and bring AED. Occasional errors were also observed when evaluates a victim's reaction or breathing. In contrast, above-mentioned tasks were finished incorrectly by $10.14 \%$ and $13.04 \%$ of workers when providing infant CPR (Tab. 4). Compared with results from adult CPR, learners more often skipped the first step (Verbalizing that the scene is safe) when providing infant CPR.

Statistically significant negative average correlations were observed between age and practical skills of the employees in CPR on adults $(R=0.65 ; p<0.01)$ and infants $(R=0.57 ; p<0.01)$. Results obtained by different age subgroups were presented in Table 5. Gender and level of education did not have a statistically significant effect on workers performance $(p>0.05)$.

In the trial, employees in the age of 35 or younger were more likely than their older colleagues to

\begin{tabular}{|c|c|c|}
\hline \multirow{2}{*}{ Critical performance steps } & \multicolumn{2}{|c|}{ Results* } \\
\hline & $n$ & $\%$ \\
\hline 1. Verbalizes that the scene is safe & 69 & 100.00 \\
\hline 2. Checks for response - tap and shout & 67 & 97.10 \\
\hline 3. Yells for help & 53 & 76.81 \\
\hline $\begin{array}{l}\text { 4. Tells someone to phone the emergency } \\
\text { response number and get an AED }\end{array}$ & 64 & 92.75 \\
\hline 5. Checks for no breathing or only gasping & 66 & 95.65 \\
\hline $\begin{array}{l}\text { 6. Locates hand placement for } \\
\text { compressions }\end{array}$ & 69 & 100.00 \\
\hline 7. Delivers first set of compressions & 69 & 100.00 \\
\hline 8. Gives 2 breaths with a mask & 69 & 100.00 \\
\hline 9. Delivers the second set of compressions & 69 & 100.00 \\
\hline 10. Gives 2 breaths with a mask & 69 & 100.00 \\
\hline $\begin{array}{l}\text { 12. Turns on the AED immediately after it } \\
\text { arrives }\end{array}$ & 68 & 98.55 \\
\hline $\begin{array}{l}\text { 13. Deliver the third set of compressions of } \\
\text { adequate depth }\end{array}$ & 69 & 100.00 \\
\hline
\end{tabular}

perform well. While providing adults CPR, members of the younger group had problems with the proper application of only one phase of the procedure which was 'Yelling for help' -3 workers made mistakes in this phase. When providing the infant CPR, only one learner failed when 'Checking for response' and other two when 'Yelling for help'. Other stages were performed correctly by all the participants in the younger group whereas the total number of errors observed in the older group reached 34.

\section{DISCUSSION}

The results obtained in this study indicate that the 'practice while watching' method may be successfully used during first aid training courses,

\begin{tabular}{|c|c|c|}
\hline \multirow{2}{*}{ Critical performance steps } & \multicolumn{2}{|c|}{ Results } \\
\hline & $\mathrm{n}$ & $\%$ \\
\hline 1. Verbalizes that the scene is safe & 65 & 94.20 \\
\hline 2. Checks for response - tap and shout & 62 & 89.86 \\
\hline 3. Yells for help & 55 & 79.71 \\
\hline 4. Checks for no breathing or only gasping & 60 & 86.96 \\
\hline $\begin{array}{l}\text { 5. Locates hand placement for } \\
\text { compressions }\end{array}$ & 67 & 97.10 \\
\hline 6. Delivers first set of compressions & 68 & 98.55 \\
\hline 7. Gives 2 breaths without a mask & 69 & 100.00 \\
\hline 8. Delivers the second set of compressions & 69 & 100.00 \\
\hline 9. Gives 2 breaths without a mask & 69 & 100.00 \\
\hline $\begin{array}{l}\text { 10. Verbalizes the need to leave to phone } \\
\text { the emergency response number }\end{array}$ & 69 & 100.00 \\
\hline $\begin{array}{l}\text { 11. Deliver the third set of compressions of } \\
\text { adequate depth }\end{array}$ & 69 & 100.00 \\
\hline *Number of workers who finished each step correctly & & \\
\hline
\end{tabular}

\begin{tabular}{|c|c|c|}
\hline & $n$ & mean \\
\hline \multicolumn{3}{|l|}{ Adults CPR } \\
\hline$\leq 35$ years & 37 & 99.4 \\
\hline$>35$ years & 32 & 94.2 \\
\hline \multicolumn{3}{|l|}{ Infants CPR } \\
\hline$\leq 35$ years & 37 & 99.3 \\
\hline$>35$ years & 32 & 90.4 \\
\hline
\end{tabular}


especially among industry workers. Its effectiveness in regard to both theoretical and practical knowledge gained by the participants was high with the average skill-set in adult and infantile CPR equal to respectively $96.9 \pm 5.2$ points and $95.2 \pm 8.8$ points out of maximum 100 points in each case. Meanwhile, estimations show that only $2.6-3.5 \%$ of the general population is able to perform adequate first aid [5]. The national survey conducted by Rasmus and Czekajlo [15] showed that although around $75 \%$ of Polish population has participated in a first aid course before, the CPR knowledge in Poland is still low and a standardized, improved curriculum is required. State of CPR knowledge displayed by younger generation is also unsatisfying, especially among individuals unrelated to medicine and healthcare [16]. Similar results were obtained also in an analogous survey performed in Norway, where theoretical CPR knowledge was surprisingly low compared with $90 \%$ of the interviewees who declared receiving first aid training in the past [17]. However, the number of CPR trained citizens varies greatly by country with $30-45 \%$ of Swedes [18] and only $12 \%$ of Hong Kong population [19]. Lower percentages of people who underwent CPR courses were observed among the elderly, foreigners and those not included in the workforce [18].

Data analysis allows observing that some points on the checklists were implemented perfectly by the whole examined group, while other stages proved to be more problematic. Both in adult and infantile CPR most mistakes were observed in step 3 (Yells for help), which was performed incorrectly respectively by $23.2 \%$ and $20.3 \%$ of examinees. In case of adult CPR evaluation the second most frequent source of mistakes was step 4 (Tells someone to phone the emergency response number and get an $\left.A E D^{\prime}\right)$, followed by, in decreasing order, step 5 (Checks for no breathing or only gasping), step 2 (Checks for response - tap and shout) and step 12 (Turns on the AED immediately after it arrives). The second leading cause of errors in infantile CPR was step 4 (Checks for no breathing or only gasping), followed by step 2 (Checks for response - tap and shout), step 1 (Verbalizes that the scene is safe), step 5 (Locates hand placement for compressions) and step 6 (Delivers first set of compressions). A possible application of these data is to provide slight differences in the teaching method and pay more attention to more problematic stages of the CPR performance, for instance repeating crucial parts and pointing out most frequent errors.

The results of our study showed no significant difference $(p>0.05)$ in regard to the gender on the skills in performing CPR on both adults and infants, which is consistent with results of some other studies [20, 21]. Peberdy et al. stipulated, however, that men may, in fact, perform CPR better and noted that the depth of the chest compressions was greater for males [22]. This is mirrored by results of Sim et al. who showed that men accomplished a significantly better median adequate depth (82.0\% vs $56.0 \%, p=0.01)$ [23]. Sayee and McCluskey concluded that both gender and body mass index (BMI) may influence the effectiveness of CPR performance [24], as males and individuals with BMI greater than 24 tend to perform CPR more effectively when using 30:2 ratio. Interestingly, no statistical difference with regards to BMI was found when a ratio 15:2 was used and the effect of gender was also less visible. Since $30: 2$ ratio was viewed to be more exhausting, the physical fitness, exercise habits and fatigue of the individual seem to play significant role in the CPR performance and their role was observed also in other studies [25-27]. Russo et al. confirmed that the chest compressions performed by female participants are too shallow, however, they also showed that good physical fitness and BMI were found to increase the quality of CPR performance independently of gender [25]. This observation may in fact partially explain the reason why our study does not demonstrate any correlation between examinee's gender and the effectiveness of their CPR performance, as industry workers possess in general more physical strength.

We found a statistically significant negative average correlation between age and practical skills of the employees in CPR on adults and infants (in both cases $p<001$ ), which is confirmed by most of the other researchers. Sim et al. showed that median adequate rate of chest compressions decreased significantly with age ( $p=0.02$ ) [23] and Peberdy et al. found that younger participants provided better depth and this effect seems to be caused by age-related decrease in physical strength and functional fitness [22]. No differences in depth and rate of compressions with age were observed in research performed by Trowbridge et al. [28]. However, authors did observe differential decline in chest compression force with older group. 
No significant difference $(p>0.05)$ was found in regard to the formal education level of the participants on the skills in performing CPR on both adult and infants after participating in the first aid training course and to our knowledge no other research of this kind has been conducted so far. Instead, the research conducted hitherto have focused mainly on influence of socioeconomic status on likelihood of first aid training in the past and rates of bystander-initiated CPR when required [29-33]. Blewer et al. found that lower education level and household income were correlated with decreased likelihood of receiving proper CPR and other studies showed that lower rates of CPR initiations by bystanders were observed in neighbourhoods of low-income, poor education and inhabited by minorities [31]. The authors' research seems to be the first to examine the connection between formal education level and post-training CPR performance and even though no correlation was found, there is a clear need for further evaluation of this phenomenon in order to provide the society with most reliable and customized CPR training tool.

We acknowledge that this study had several limitations, especially with convenient and limited in size sample and as a result it should not be generalized to represent general population of industry workers, but it can be assumed that data we obtained may be used to provide better understanding in similar cases.

\section{CONCLUSIONS}

This research shows that 'practice while watching' method of first aid training may serve as a valuable tool in provision of CPR knowledge among chemical industry employees and its high effectiveness may arise from systematic repetition of skills both individual and incorporated into full CPR algorithm for a sufficient period of time. The authors did not observe any statistically significant differences regarding gender and formal education level on CPR performance, however, age seems to affect the quality of skills of the employees in CPR on both adults and infants.

Source of support: This work was supported by Poznan University of Medical Sciences (grant number 502-01-04102108-05274).

Declarations of interest: The authors report no competing interests.

\section{REFERENCES}

1. Bakar Che Man A, Gold D. Safety and Health in the Use of Chemicals at Work: A Training Manual. Geneva, International Labour Office. 1993.

2. Hadhri M. Facts \& figures of the European chemical industry. 2016. http://www.apdcr.ro/en/files/Cefic_Facts \& Figures 2016 report_11.10.2016.pdfweb.pdf (13.03.2018).

3. Aylaz R, Gözüm S, Yılmaz U, et al. The Efficacy of the First Aid Training Program for Apprenticeship Students. İnönü Üniversitesi Tıp Fakültesi Derg. 2009; 16(2): 89-94.

4. Nag PK, Patel VG. Work accidents among shiftworkers in industry. Int J Ind Ergon 1998; 21(3-4. : 275-81.

5. Hatzakis KD, Kritsotakis El, Angelaki HP, et al. FirstAid knowledge among industry workers in Greece. Ind Health. 2005; 43(2): 327-332, doi: 10.2486/indhealth.43.327, indexed in Pubmed: 15895848.

6. Johnson KA, Ruppe J. A job safety program for construction workers designed to reduce the potential for occupational injury using tool box training sessions and computer-assisted biofeedback stress management techniques. Int J Occup Saf Ergon. 2002; 8(3): 321-329, doi: 10.1080/10803548.2002.11076532, indexed in Pubmed: 12189103.

7. Peksen $Y$, Dabak $S$. The role of ersonal rotectors and training in industrial injuries. In: National Community Health Congress. Didim. 1994: 477-479.

8. Dieterich BH. The Organization of First Aid in the Workplace. Geneva, International Labour Office. 1989.

9. Szarpak A. Organization of trauma centres in Poland. . Disaster Emerg Med J. 2019; 4(2): 55-59, doi: 10.5603/DEMJ.2019.0011.

10. Lingard $\mathrm{H}$. The effect of first aid training on Australian construction workers' occupational health and safety motivation and risk control behavior. J Safety Res. 2002; 33(2): 209-230, doi: 10.1016/s00224375(02)00013-0, indexed in Pubmed: 12216447.

11. Czekajlo M, Dabrowska A. In situ simulation of cardiac arrest. Disaster Emerg Med J. 2017; 2(3): 116-119, doi: 10.5603/DEMJ.2017.0025.

12. Abelsson A. Learning through simulation. Disaster Emerg Med J. 2017; 2(3): 125-128, doi: 10.5603/DEMJ.2017.0027.

13. Abelsson A, Lundberg L. Prehospital CPR training performed with visual feedback. Disaster Emerg Med J. 2018; 3(2): 41-45, doi: 10.5603/DEMJ.2018.0010.

14. Gonzales L, Lynch MW, BorkS. Heartsaver ${ }^{\circledR}$ First Aid CPR AED Instructor Manual Dallas. American Heart Association. 2013.

15. Rasmus A, Czekajlo MS. A national survey of the Polish population's cardiopulmonary resuscitation knowledge. Eur J Emerg Med. 2000; 7(1): 39-43, doi: 10.1097/00063110-200003000-00008.

16. Czyzewski L, Sobieski A, Michalak J, et al. Assessment of First Aid Knowledge Among Medical and Non-Medical University Students. Disaster Emerg Med J. 2017; 2(4): 150-154, doi: 10.5603/ DEMJ.2017.0034.

17. Bakke HK, Steinvik T, Angell J, et al. A nationwide survey of first aid training and encounters in Norway. BMC Emerg Med. 2017; 17(1): 6, doi: 10.1186/s12873-017-0116-7, indexed in Pubmed: 28228110.

18. Axelsson $A B$, Herlitz J, Holmberg $S$, et al. A nationwide survey of CPR training in Sweden: foreign born and unemployed are not reached 
by training programmes. Resuscitation. 2006; 70(1): 90-97, doi: 10.1016/j.resuscitation.2005.11.009, indexed in Pubmed: 16757090.

19. Cheung BMY, Ho C, Kou KO, et al. University Of Hong Kong Cardiopulmonary Resuscitation Knowledge Study Group. Knowledge of cardiopulmonary resuscitation among the public in Hong Kong: telephone questionnaire survey. Hong Kong Med J. 2003; 9(5): 323-328, indexed in Pubmed: 14530525.

20. Ock SM, Kim YM, Chung Juh, et al. Influence of physical fitness on the performance of 5-minute continuous chest compression. Eur J Emerg Med. 2011; 18(5): 251-256, doi: 10.1097/MEJ.0b013e328345340f, indexed in Pubmed: 21593673.

21. Ochoa FJ, Ramalle-Gómara $E$, Lisa $V$, et al. The effect of rescuer fatigue on the quality of chest compressions. Resuscitation. 1998; 37(3): 149-152, doi: 10.1016/50300-9572(98)00057-4, indexed in Pubmed: 9715774.

22. Peberdy MA, Silver A, Ornato JP. Effect of caregiver gender, age, and feedback prompts on chest compression rate and depth. Resuscitation. 2009; 80(10): 1169-1174, doi: 10.1016/j.resuscitation.2009.07.003, indexed in Pubmed: 19674826.

23. Sim Z, White A, Wah $W$, et al. 42 Assessing factors affecting the quality of chest compressions during training for laypersons using a novel CPRCARD. Emergency Medicine Journal. 2017; 34(12): A889, doi: 10.1136/emermed-2017-207308.42.

24. Sayee N, McCluskey D. Factors influencing performance of cardiopulmonary resuscitation (CPR) by Foundation Year 1 hospital doctors. Ulster Med J. 2012; 81(1): 14-18, indexed in Pubmed: 23536733.

25. Russo SG, Neumann P, Reinhardt $S$, et al. Impact of physical fitness and biometric data on the quality of external chest compression: a randomised, crossover trial. BMC Emerg Med. 2011; 11: 20, doi: 10.1186/1471-227X-11-20, indexed in Pubmed: 22053981.

26. Lin CC, Kuo CW, Ng CJ, et al. Rescuer factors predict high-quality CPR--a manikin-based study of health care providers. Am J Emerg
Med. 2016; 34(1): 20-24, doi: 10.1016/j.ajem.2015.09.001, indexed in Pubmed: 26431945.

27. Barcala-Furelos R, Abelairas-Gomez C, Romo-Perez V, et al. Effect of physical fatigue on the quality CPR: a water rescue study of lifeguards: physical fatigue and quality CPR in a water rescue. Am J Emerg Med. 2013; 31(3): 473-477, doi: 10.1016/j.ajem.2012.09.012, indexed in Pubmed: 23085007.

28. Trowbridge C, Parekh JN, Ricard MD, et al. A randomized cross-over study of the quality of cardiopulmonary resuscitation among females performing 30:2 and hands-only cardiopulmonary resuscitation. BMC Nurs. 2009; 8: 6, doi: 10.1186/1472-6955-8-6, indexed in Pubmed: 19583851.

29. Fosbøl EL, Dupre ME, Strauss B, et al. Association of neighborhood characteristics with incidence of out-of-hospital cardiac arrest and rates of bystander-initiated CPR: implications for community-based education intervention. Resuscitation. 2014; 85(11): 1512-1517, doi: 10.1016/j.resuscitation.2014.08.013, indexed in Pubmed: 25180920.

30. Root ED, Gonzales L, Persse DE, et al. A tale of two cities: the role of neighborhood socioeconomic status in spatial clustering of bystander CPR in Austin and Houston. Resuscitation. 2013; 84(6): 752-759, doi: 10.1016/j.resuscitation.2013.01.007, indexed in Pubmed: 23318916.

31. Blewer AL, Ibrahim SA, Leary M, et al. Cardiopulmonary Resuscitation Training Disparities in the United States. J Am Heart Assoc. 2017; 6(5), doi: 10.1161/JAHA.117.006124, indexed in Pubmed: 28515114.

32. Sasson C, Keirns CC, Smith DM, et al. Examining the contextual effects of neighborhood on out-of-hospital cardiac arrest and the provision of bystander cardiopulmonary resuscitation. Resuscitation. 2011; 82(6): 674-679, doi: 10.1016/j.resuscitation.2011.02.002, indexed in Pubmed: 21458136

33. Becker LB, Han BH, Meyer PM, et al. Racial differences in the incidence of cardiac arrest and subsequent survival. The CPR Chicago Project. N Engl J Med. 1993; 329(9): 600-606, doi: 10.1056/ NEJM199308263290902, indexed in Pubmed: 8341333. 